\title{
Is shared learning the way to bring UK neurology and psychiatry closer: what teachers, trainers and trainees think
}

\author{
F Schon, A MacKay, C Fernandez
}

See end of article for authors' affiliations

(n)

Correspondence to: Dr F Schon, Mayday University Hospital, London Road, Thornton Heath CR7 TYE, UK; frederick.schon@mayday. nhs.co.uk

Received 17 August 2005 Revised version received 8 March 2006 Accepted 9 March 2006

Published Online First 28 April 2006
Background: Rapid advances in brain sciences are challenging the validity of the traditional divide between neurology and psychiatry. The need for closer ties has been widely advocated.

Objective: To assess attitudes of neurologists and psychiatrists to closer links in general and to joint education in particular.

Methods: Postal questionnaire survey of trainees (SpRs) trainers (Members of Special Advisory Committees in Neurology and General and Old Age Psychiatry) and teachers (Undergraduate coordinators). Analysis based on 55 neurology and 50 psychiatry respondents.

Results: 5 general attitude questions on links showed most respondents "keen" on links and "unkeen" on current separation of disciplines. 15 topics possibly suitable for joint teaching were offered. 7 were rated between "keen" and very "keen" with maximum support for somatization, dementia, chronic pain and pharmacology. 7 were rated positively, only eating disorders was felt unsuitable. 6 options were offered for joint training opportunities. Trainees were keen on attending joint education, clinical and patient management sessions and outpatient clinics. Psychiatrists were even keener on links than neurologists with psychiatric SpRs significantly more in favour of certain items.

Conclusions: The survey found widespread support from trainees, trainers and teachers for closer links. Trainees were keen to attend joint clinically focussed sessions. Psychiatrists tended to be keener that neurologists on links. This survey should encourage the establishment of closer educational links at all levels. c urrently, the practice of neurology and psychiatry in the UK is effectively completely separate. The critical reason for reassessing this issue is the explosion of knowledge in basic brain sciences, which underpin both disciplines. Many experts have argued in recent years that this new situation is effectively redefining both disciplines and perhaps, in particular, moving psychiatry closer to neurology. ${ }^{1-7}$

Neurology is currently mostly practised in hospitals with major links to general and acute medicine and psychiatry deals with mainly chronic disease, often in a community setting. These vast practical differences make it difficult to see how the specialties may come closer in the near future. One potential way of bridging this divide would be by linking undergraduate and postgraduate teaching and training, which are at present poles apart.

This study is a questionnaire-based survey looking at attitudes to educational and training links focusing separately on undergraduate teaching and postgraduate training. The three groups whose opinions were sought were

1. Undergraduate coordinators of both neurology and psychiatry teaching in all UK medical schools.

2. Trainers-all members of the specialist advisory committees (SACs) of the Royal Colleges of Physicians in Neurology and of the SAC of the Royal College of Psychiatrists in General and Old Age Psychiatry.

3. Trainees-specialist registrars (SpRs) in both neurology and psychiatry.

\section{METHODS}

A short questionnaire was sent by post to all the three groups. The questionnaire had two core sections.
Section l looked at general attitudes to links and was entitled "How do you feel about the following opinions?" The section consisted of five questions, each followed by five options ranging from strongly disagree to strongly agree.

1. The teaching of clinical neurology and psychiatry should be closely linked since both deal with disorders of the central nervous system.

2. The teaching of clinical neurology and psychiatry should be kept separate since clinical practice in the specialities is different.

3. The teaching of clinical neurology and psychiatry should be linked to reduce the differences in clinical practice.

4. Do you personally think the issue of greater integration of neurology and psychiatry training is important?

5. Do you personally favour closer links between neurology and psychiatry training?

Section 2 gave a list of common topics or diagnoses ( 13 in the undergraduate and 15 in the postgraduate version) potentially suitable for integrated teaching, and asked how much the respondent believed each subject lent itself to integrated teaching, again offering the same five options.

The questionnaire given to undergraduate coordinators contained a third section asking about current teaching arrangements for neurology and psychiatry in each medical school.

The questionnaires to SpRs and SACs contained a third section, which asked about attitudes towards six different types of joint potential teaching sessions or attachments: joint educational meetings, a formal 3-month attachment,

Abbreviations: SAC, specialist advisory committee; SpR, specialist registrar 
outpatient clinics, clinical meetings on disease management (such as ward rounds), emergency on-call observation and hospital and community meetings on chronic patient management.

The final part asked the SpRs: "Would you personally wish to attend integrated teaching sessions?"

The SAC version asked two similar questions: "Would you personally wish to be involved in setting up integrated teaching sessions?" "Do you feel some integrated teaching sessions for both sets of registrars is a realistic ten year ambition?"

All three questionnaires ended with a section asking for general comments on education and links.

The undergraduate version was sent to the 26 UK medical schools, the SAC version to all 15 members of the Neurology Committee and the 16 members of the General and Old Age Psychiatry SAC and the SpR version to 80 registrars, 40 from each discipline.

Neurology trainees were selected from the Association of British Neurologists database and psychiatrists from the South Thames General and Old Age Psychiatry database.

The results were calculated by giving a score of $0-4$ for each question, all of which offered five options, with 4 being the most positive response: 0 , very unkeen; 1 , unkeen; 2, neutral; 3, keen; 4, very keen.

Data were coded for group membership using Microsoft Excel V.2000. Independent sample t tests were examined for intergroup responses, and also between the overall divisions of neurology and psychiatry. Levene's test was used to assess equality of variance. The statistical software used was SPSS V.12 for Microsoft Windows V.2000.

\section{RESULTS}

We obtained a high overall response rate:

- $65 \%$ from undergraduate coordinators

- $61 \%$ from SAC members

- $69 \%$ from SpRs

In all three groups, response rates from neurologists and psychiatrists were similar.

\section{Undergraduate links}

In the undergraduate survey, at least one reply was received from 22 of the 26 medical schools approached. The following seven schools already had close links in undergraduate teaching: Dundee, Edinburgh and Liverpool, and The Royal Free, St George's, The Royal London and King's, Guy's and St Thomas's Hospitals in London. These links usually included several weeks of neurology teaching, followed by a usually longer period of psychiatry teaching. With rare exceptions, there is currently no joint teaching when neurologists and psychiatrists run shared sessions. In Brighton, Hull and Manchester, there are some links in the curriculum, but the remaining 12 medical schools have few or no connections. Psychiatry showed close links to primary care in six medical schools, neurology to ophthalmology in six and to general medicine in three medical schools.

\section{General attitude questions}

Table 1 shows the mean response to the five general attitude questions, giving the results for all three groups surveyed and from both disciplines. More than $75 \%$ of those responding were personally for closer links (score $2.7-3.1$ ), only $20 \%$ believed that the subjects should be kept separate (score 1.21.6) and $75 \%$ believed that integrated teaching was an important issue.

We found a trend in responses from the two disciplines, with psychiatrists being keener than neurologists on links.
Table 1 Mean score of responses to general attitude questions

\begin{tabular}{llll}
\hline & $\begin{array}{l}\text { Neurologists } \\
(\mathbf{n}=56)\end{array}$ & $\begin{array}{l}\text { Psychiatrists } \\
(\mathbf{n}=50)\end{array}$ & $\begin{array}{l}\text { Both } \\
(\mathbf{n}=106)\end{array}$ \\
\hline $\begin{array}{l}\text { Link teaching as both deal } \\
\text { with the brain }\end{array}$ & 2.6 & 2.9 & 2.8 \\
$\begin{array}{l}\text { Keep separate to reflect } \\
\text { current practice }\end{array}$ & 1.6 & 1.2 & 1.4 \\
$\begin{array}{l}\text { Link teaching to reduce } \\
\text { differences }\end{array}$ & 2.6 & 2.9 & 2.7 \\
$\begin{array}{l}\text { Integrated teaching is } \\
\text { important }\end{array}$ & 2.8 & 3.0 & 2.9 \\
Personally for closer links & 2.9 & 3.2 & 3.1 \\
\hline
\end{tabular}

0 , strongly disagree; 1 , disagree; 2 , neutral; 3 , agree; 4 , strongly agree.

Table 2 Mean score of support for joint topic teaching

\begin{tabular}{llll}
\hline Condition & Neurologists & Psychiatrists & Both \\
\hline Somatisation & 3.5 & 3.4 & 3.5 \\
Dementia & 3.4 & 3.4 & 3.4 \\
Chronic pain & 3.1 & 3.4 & 3.3 \\
Pharmacology & 3.0 & 3.5 & 3.2 \\
Chronic fatigue & 3.1 & 3.3 & 3.2 \\
Epilepsy* & 2.8 & 3.6 & 3.2 \\
Head injury & 2.8 & 3.6 & 3.2 \\
Parkinson's disease & 2.5 & 3.4 & 2.9 \\
Sleep & 2.5 & 3.0 & 2.8 \\
Multiple sclerosis* & 2.3 & 3.3 & 2.8 \\
Post-traumatic stress & 2.5 & 2.4 & 2.5 \\
disorder & & & \\
Substance misuse & 2.2 & 2.6 & 2.4 \\
Aggression & 2.2 & 2.6 & 2.4 \\
Schizophrenia & 2.0 & 2.4 & 2.2 \\
Eating disorders & 1.8 & 2.0 & 1.9 \\
\hline *Epilepsy and multiple sclerosis were not in the undergraduate teaching \\
questionnaire.
\end{tabular}

This reached significance at $\mathrm{p}<0.05$ for the SpRs for the first, third and fifth statements.

\section{Topic teaching}

Table 2 shows the support for integrated teaching on the 15 topics as total mean responses from all the three groups surveyed.

We observed massive support for joint teaching on somatisation, dementia, chronic pain, neuropharmacology chronic fatigue syndrome, epilepsy and head injury from both neurologists and psychiatrists, with mean scores of 33.5. Support for seven of the other topics was positive, with mean scores of $2-3$, and a clear lack of interest was seen only in joint teaching on eating disorders.

The responses were not statistically different among the whole group, but psychiatrists were keener than neurologists on joint teaching for 12 of the 15 topics.

The SpR results, in contrast, were statistically different on five topics, with psychiatry trainees keener on joint teaching

Table 3 Mean score of level of support for joint sessions

\begin{tabular}{llll}
\hline & Neurologists & Psychiatrists & Both \\
\hline Clinical meetings & 3.2 & 3.4 & 3.3 \\
Outpatient clinics & 3.1 & 3.3 & 3.2 \\
Educational meetings & 3.0 & 3.3 & 3.2 \\
Management of patients & 2.9 & 3.1 & 3.0 \\
3-month attachment & 2.7 & 3.2 & 2.9 \\
On call & 2.4 & 2.5 & 2.4 \\
\hline
\end{tabular}




\begin{tabular}{|c|c|c|c|}
\hline & Neurologists & Psychiatrists & Both \\
\hline $\begin{array}{l}\text { Special registrars } \\
\text { keen to attend }\end{array}$ & 3.2 & 3.3 & 3.2 \\
\hline $\begin{array}{l}\text { Specialist advisory } \\
\text { committee keen to } \\
\text { arrange }\end{array}$ & 3.1 & 2.7 & 2.9 \\
\hline Realistic ambition & 3.3 & 3.00 & 3.2 \\
\hline
\end{tabular}

of epilepsy, head injury, multiple sclerosis, neuropharmacology and Parkinson's disease $(\mathrm{p}<0.01-0.001)$.

\section{Joint training opportunities}

The SpRs and trainers were asked about support for six different potential joint training opportunities (table 3).

We found that major support was shown for five of the six opportunities, with maximum support for joint clinical meetings and outpatient clinics. Interest was indicated, particularly by psychiatrists, for a 3-month attachment. Least support was shown for observing "out of hours on call" work. All six options were favoured more by psychiatrists than by neurologists. This was significantly different at $p<0.05$, with SpRs in psychiatry being significantly keener on joint educational meetings and a 3-month attachment.

Trainees were asked how keen they personally were to attend joint sessions and their scores disclosed great interest (table 4). Trainers were slightly less keen to participate in setting up joint sessions, but most thought it was a realistic 10-year ambition.

Supplementary general comments were made by $73 \%$ of the undergraduate coordinators, $45 \%$ of the SpRs and $37 \%$ of the SAC members. Some particularly interesting comments are reported below.

Undergraduate coordinators pointed out the following general issues:

- The enormous practical difficulties in changing undergraduate curriculums.

- The importance of not abandoning links between psychiatry and primary care.

- Some psychiatrists thought that neurologists were not keen on links. The converse was not reported.

The following are some comments from individual undergraduate coordinators:

- I would not want to give medical students the idea that neurology is a vague and undefined discipline.

- For conversion or dissociative disorders, it would prevent patients falling between two stools.

- The big issue for neurology is a pragmatic one. Many of our patients have a psychiatric dimension.

- The ethos in France and the US or Canada is more friendly to integration.

- I think there is a crisis in critical thought in psychiatry and closer alignment with neurology would help.

Some comments from individual SAC members are as follows:

- Joint or integrated teaching is much more a SHO (senior house officer) issue than a registrar one.

- The Royal College of Physicians and the Royal College of Psychiatrists need to get together to sort this out.

- Psychiatry needs to change a lot more than neurology.
- Integrated approach to teaching should apply to both subjects from medical school onwards. This is of major importance in Old Age psychiatry.

A selection of comments from psychiatry SpRs is given below:

- More training should be provided for brain imaging and neurogenetics.

- I am concerned not to lose psychotherapeutic understanding.

- I think integration will add to medical bias already present in psychiatry in the UK.

- I am concerned with the mind rather than the nervous system.

- It is important not to lose the psychological angle.

Selected comments from neurology SpRs are as follows:

- Some aspects lend themselves to integrated teaching but would need to be at completely different levels for the two disciplines.

- Clinical practice is very different.

- A ridiculous number of subspecialty topics on the curriculum already exists.

- Neurology needs close links with medicine and the trend to brain sciences will undermine that.

\section{DISCUSSION}

This survey has looked at attitudes to a more integrated approach to teaching and training in neurology and psychiatry. The study targeted two small but influential groups of educators, one engaged in organising undergraduate teaching and the other responsible for postgraduate training. The third group comprised unselected SpRs from both disciplines. The high response rate from all three groups $(>60 \%)$ may suggest that the results reflect the views of each target group.

The main conclusion common to all three groups and both disciplines is a widespread, high level of support and interest in teaching and training links. Support was equally strong among trainees who were unselected, as among educators who, by virtue of their positions, were selected for their interest in education and training.

The results are in agreement with those expressed in recent years by many leading experts in basic neuroscience, ${ }^{1-4}$ as well as clinical neurology and psychiatry..$^{4-6}$ Their importance, however, may lie in the fact that they are perhaps the first to show how widespread these ideas are at the grassroots level.

The need for both disciplines to redefine themselves in the light of advances in brain science has been emphasised by the Nobel prize winner Eric Kandell ${ }^{1-3}$ and Vilayamir S Ramachandran, ${ }^{4}$ the BBC Reith lecturer for 2003, who took a rather one-sided view when he said, "The boundary between neurology and psychiatry is becoming increasingly blurred and it's only a matter of time before psychiatry becomes just another branch of neurology".

The central role that redesigned education programmes in both neurology and psychiatry should have in this process has been particularly advocated by the Harvard Medical School. Price et $a l^{6}$ in 1999 entitled their essay "Neurology and psychiatry-closing the great divide". A similar plea was made in 2002 in a $B M J$ editorial" entitled "The wall between neurology and psychiatry-advances in neuroscience indicate it is time to tear it down".

The second finding was that, although neurologists were keen, they tended to be less keen on links than psychiatrists. This is perhaps surprising, as the importance of psychiatry to 
everyday neurological practice was recently emphasised when it was shown that as many as one third of new outpatient attendees have so-called medically unexplained symptoms. ${ }^{8}$ The need for neurology as well as psychiatry to change was pointed out by Stone and Sharpe ${ }^{9}$ when they wrote "Will a greater understanding of neuroscience mean that psychiatry will simply follow neurology in abandoning the patients that fail to fit into a reductionist paradigm?"

The desirability of neurologists forging wider links, including those with psychogeriatrics in management of dementia, is central to the 2003 document of the Association of British Neurologists, ${ }^{10}$ UK neurology-the next ten years. Likewise, the importance of neurology being seen as more "user friendly" by non-neurologists and medical students has also been advocated. ${ }^{11}{ }^{12}$

The justification for establishing educational links is to improve patient care. We believe that bringing the two disciplines closer will extend the spectrum of knowledge and skills of both specialties: neurologists can gain greater expertise in many aspects of chronic, community-based care as well as in "soft" syndromes (medically unexplained symptoms), and psychiatrists in the diagnosis, investigation and management of patients with relevant brain disorders. The gap between diseases of the mind and the brain is narrowing all the time. Recent papers have used neuroimaging to look at the effects of psychotherapy, and one group showed changes in hippocampal volumes during treatment for post-traumatic stress disorder. ${ }^{13}{ }^{14}$

A reappraisal is needed, starting at undergraduate level, through junior doctor training and now also through consultant continuing medical education, reflecting the narrowing of the gap between mind and brain diseases, which in reality is an outdated concept. Each medical school should increasingly link the teaching of basic neuroscience, psychiatry, neurology and psychology.

Currently, senior house officers and SpRs in both neurology and psychiatry are being taught the major overlap topics, such as dementia, somatisation, pharmacology, head injury, chronic pain and others, in total isolation, by different "ologists", in different places and at different times, although often in the same institutions.

These results strongly suggest that trainees and trainers are open to a more integrated approach. One potential development is the establishment of a basic clinical neuroscience training programme as part of the new foundation years. This would enable junior doctors considering specialising in neurology, neurosurgery, psychiatry, rehabilitation medicine and elderly care medicine to attend a neurology attachment before starting specialist training. Another approach would be to establish joint training days for both sets of SpRs in each discipline, covering topics of mutual relevance.

In conclusion, we hope that these results will embolden those overseeing postgraduate training (the Royal Colleges of Medicine and Psychiatry, and the Postgraduate Medical Education and Training Board) to begin the process of bringing education in neurology and psychiatry closer.

\section{ACKNOWLEDGEMENTS}

We thank Professor Charles Warlow and Dr Michael Sharp for their helpful comments on the manuscript.

\section{Authors' affiliations}

F Schon, Department of Neurology, Atkinson Morley Wing, St George's Hospital, London, UK

A MacKay, Argyll \& Bute Hospital, Lochgilphead, Scotland

C Fernandez, Mayday University Hospital, Thornton Heath, UK

Competing interests: None declared.

\section{REFERENCES}

1 Kandel ER. A new intellectual framework for psychiatry. Am J Psychiatry 1998;155:457-69.

2 Kandel ER. Biology and the future of psychoanalysis: a new intellectual framework for psychiatry revisited. Am J Psychiatry 1999;156:505-24.

3 Cowan WM, Kandel ER. Prospects for neurology and psychiatry. JAMA $2001 ; 285: 594-600$.

4 Ramachandran VS. The emerging mind. Reith Lecture Series. London: Profile Books, 2003.

5 Martin JB. The integration of neurology, psychiatry, and neuroscience in the 21 st century. Am J Psychiatry 2002;159:695-704.

6 Price BH, Adams RD, Coyle JT. Neurology and psychiatry-closing the gap. Neurology 2000;54:8-14

7 Baker M, Kale R, Menken M. The wall between neurology and psychiatryadvances in neuroscience indicate it's time to tear it down. BMJ 2002;324: 1468-9.

8 Carson AJ, Ringaver B, Stone J, et al. Do medically unexplained symptoms matter? A prospective cohort study of 300 new referrals to neurology outpatient clinics. J Neurol Neurosurg Psychiatry 2000;68:207-10

9 Stone J, Sharpe M. Neurology, psychiatry and neuroscience. Am J Psychiatry 2003;160:1013-4.

10 Association of British Neurologists. UK neurology-the next ten years. London: Association of British Neurologists, 2003.

11 Schon F, Hart P, Fernandez C. Is clinical neurology really so difficult? J Neurol Neurosurg Psychiatry 2002;72:557-9.

12 Menken $M$. Demystifying neurology - phenomenology can help. BMJ 2002;324: 1469-70.

13 Roffman JL, Marci CD, Glick DM, et al. Neuroimaging and the functional neuroanatomy of psychotherapy. Psychol Med 2005;35: 1385-98.

14 Lindauer RJL, Vlieger EJ, Jalink M, et al. Effects of psychotherapy on hippocampal volume in out patients with post-traumatic stress disorder; an MRI investigation. Psychol Med 2005;35:1421-31. 